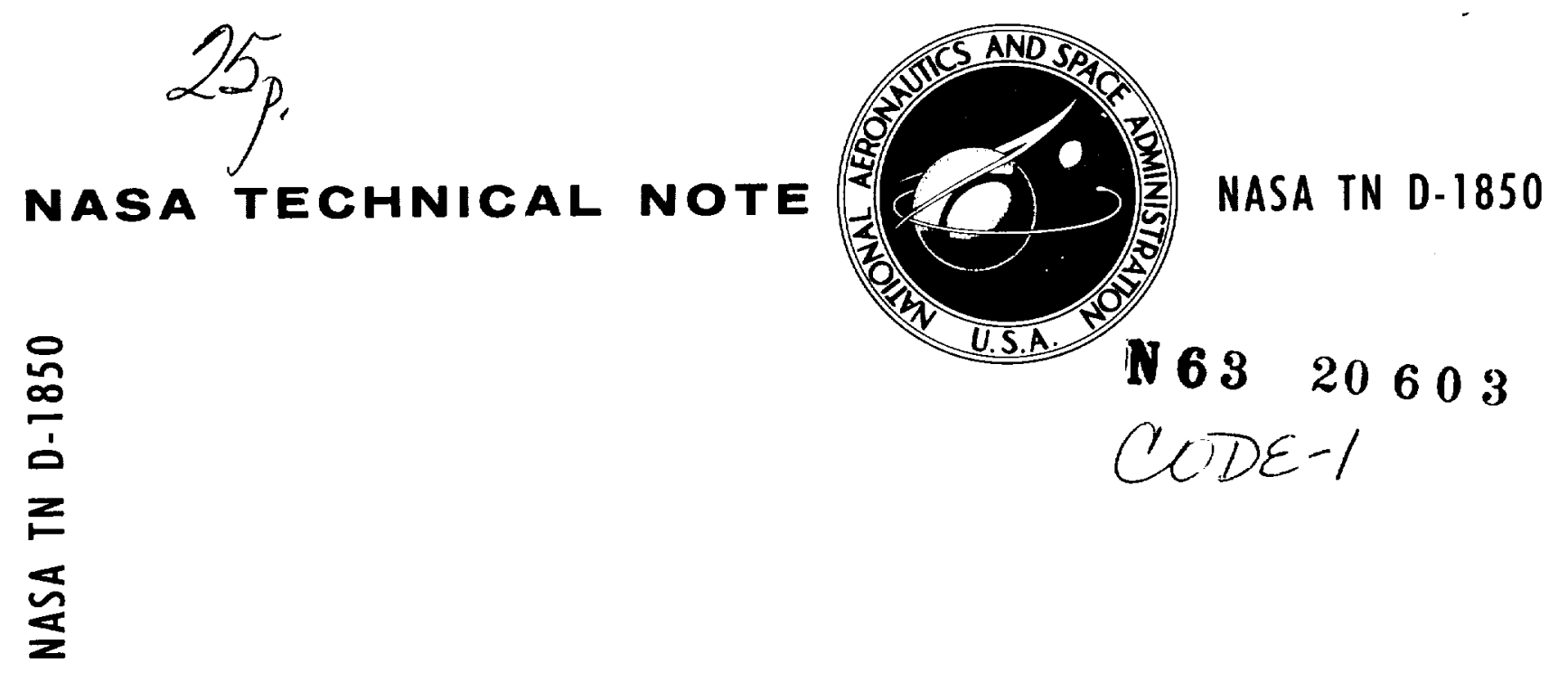

\title{
THE INFRARED HORIZON OF THE PLANET EARTH
}

by R. A. Hanel, W. R. Bandeen, and B. J. Conrath; Goddard Space Flight Center, Greenbelt, Maryland

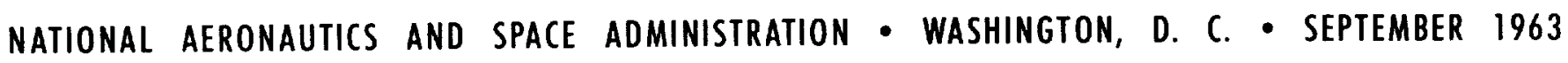




\section{CASE FILE COPY}


TECHNICAL NOTE D-1850

THE INFRARED HORIZON OF THE PLANET EARTH

By R. A. Hanel, W. R. Bandeen, and $\mathrm{B}$. J. Conrath

Goddard Space Flight Center

Greenbelt, Maryland 



\title{
THE INFRARED HORIZON OF THE PLANET EARTH
}

\author{
by \\ R. A. Hanel, W. R. Bandeen, and \\ B. J. Conrath \\ Goddard Space Flight Center
}

SUMMARY

$$
20603
$$

Horizon sensors are essential elements in the orientation systems of many space vehicles and satellites. The design of horizon sensors, as well as an evaluation of their capabilities and limitations, requires a knowledge of the spectral radiance emitted by the earth. This report investigates the discontinuity between the surface, the atmosphere, and outer space for various latitudinal, seasonal, climatic, and meteorological conditions. Calculations are carried out for the following five spectral intervals: the water vapor band from 6.33 to 6.85 microns, the ozone band from 8.9 to 10.1 microns, the atmospheric window from 10.75 to 11.75 microns, the carbon dioxide band from 14 to 16 microns, and finally the rotational water vapor band from 21 to 125 microns. The superior properties of the carbon dioxide band and the rotational water vapor region for horizon sensor purposes are shown. 

CONTENTS

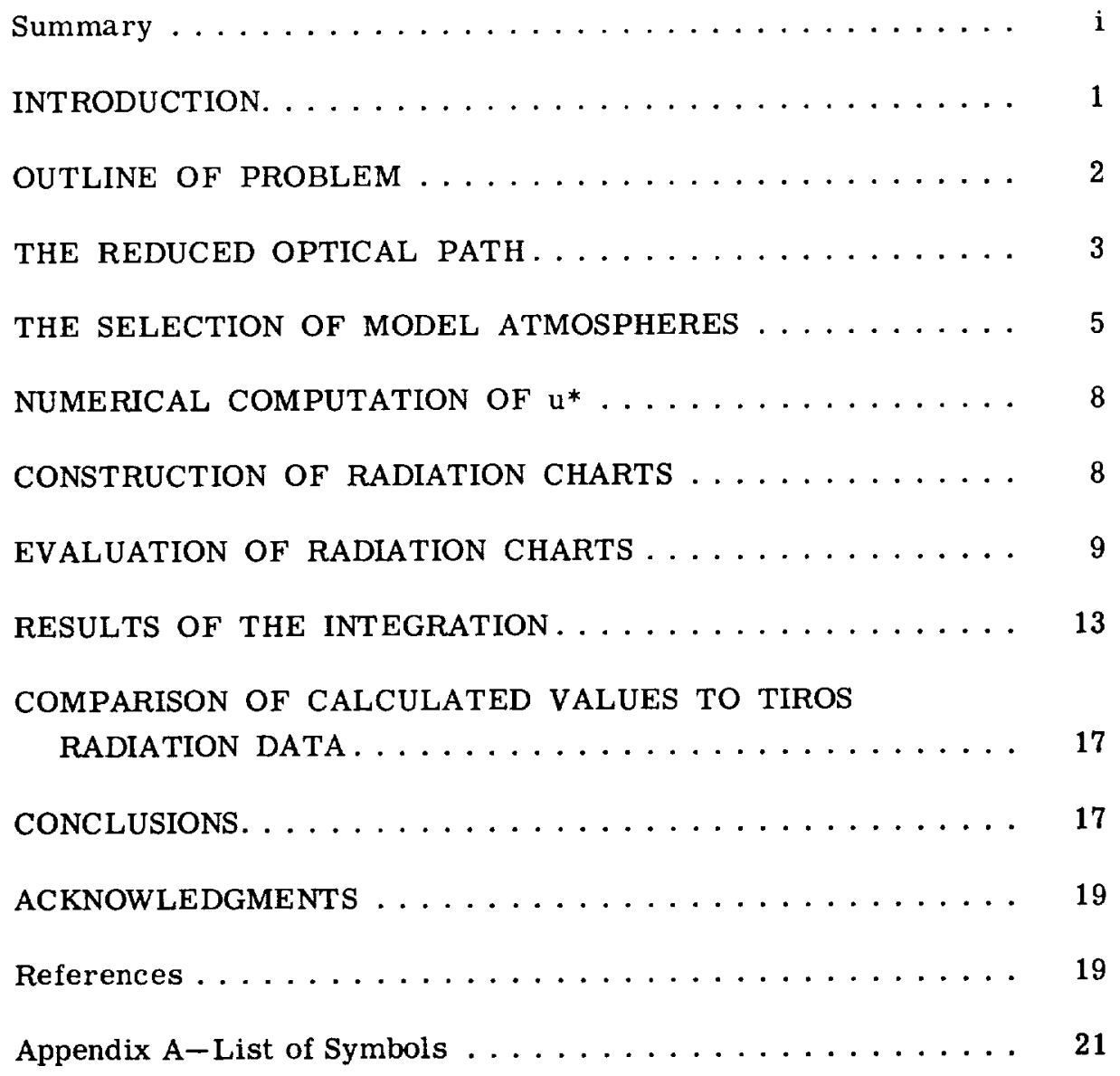


- 


\title{
THE INFRARED HORIZON OF THE PLANET EARTH*
}

\author{
by \\ R. A. Hanel, W. R. Bandeen, and \\ B. J. Conrath \\ Goddard Space Flight Center
}

\section{INTRODUCTION}

A knowledge of the direction toward the center of the earth is required for the proper orientation of many scientific satellites and manned space capsules. Moreover, the required accuracy in determining the direction of the local vertical is constantly increasing with the growing sophistication and complexity of experiments.

Normally, a horizon sensor system determines the center of the apparent disk of the earth, which is very close to the center of gravity. In order to make the system independent of sunlight, it has become customary to restrict the spectral response of the horizon sensor to the infrared part of the spectrum or, more specifically, to wavelengths longer than 2 microns. For the sake of simplicity and engineering convenience the spectral response has seldom been extended much beyond 15 microns (e.g., Reference 1). This utilizes about one-half the energy of a $270^{\circ} \mathrm{K}$ blackbody, which is very important for normally energy limited systems.

This approach is entirely justified as long as one is satisfied with an uncertainty in the horizon on the order of $50 \mathrm{~km}$ (about 1 degree for a $600 \mathrm{~km}$ orbit) and as long as the system is able to accommodate the changes in signal strength caused by varying meteorological conditions (Reference 2 ). Only recently have horizon sensors that are more selective spectrally been considered. ${ }^{\dagger}$ However, for the design of advanced stabilization systems, a better understanding of the infrared structure of the horizon is required.

This report investigates the discontinuity between the earth, the atmosphere, and outer space. The apparent horizon was computed for several wavelength regions and under a variety of atmospheric conditions. Latitudinal, seasonal, and climatic effects were considered, as well as the effect of clouds for several altitudes. Calculations are given in detail to benefit the reader who is interested in the problem of horizon sensing but who may not be familiar with the problems in the radiative transfer of energy.

\footnotetext{
Also published in: Jour. Atm. Sci. (March 1963).

tPrivate communication from D. Goetze, 1962.
} 
While writing this paper, the authors discovered that a similar investigation, although for somewhat different spectral intervals and model atmospheres, had been carried out recently by $\mathrm{K}$. $\mathrm{Y}$. Kondratiev and K. E. Yakushevskaya at the University of Leningrad, U.S.S.R. (Reference 3). For ease in comparing the two papers, the present results are plotted herein (Figures 10 through 14) in a format similar to that used by Kondratiev and Yakushevskaya.

\section{OUTLINE OF PROBLEM}

In the spectral range of infrared emission, the sharpness of the horizon depends on the vertical temperature and pressure profiles and on the distribution of absorbing (and therefore emitting) matter in the atmosphere. Water vapor, carbon dioxide, and ozone have strong absorption bands in this range, which must be considered. In addition, droplets and ice crystals in clouds, and perhaps dust and aerosols, must also be included.

An attempt has been made to compute the fraction of the radiance $N\left(w / m^{2}-s t e r\right)$ of the earth and the atmosphere within particular wavelength regions where only one of the atmospheric constituents dominates absorption. Less important constituents have been considered qualitatively only, with the exception of the 8.9 to 10.1 micron region, where emission by ozone and the water vapor continuum both are taken into account. The wavelength intervals considered are listed in Table 1.

Table 1

Wavelength Intervals Considered.

\begin{tabular}{|c|l|l|}
\hline Wavelength (microns) & Major Absorber & Secondary Absorbers \\
\hline $6.33-6.85$ & $\mathrm{H}_{2} \mathrm{O}$ & None \\
$8.9-10.1$ & $\mathrm{O}_{3}$ & $\mathrm{H}_{2} \mathrm{O}$ continuum \\
$10.75-11.75$ & $\mathrm{H}_{2} \mathrm{O}$ continuum & Dust \\
$14-16$ & $\mathrm{CO}_{2}$ & $\mathrm{O}_{3}, \mathrm{H}_{2} \mathrm{O}$ \\
21 & $\mathrm{H}_{2} \mathrm{O}$ & None \\
\hline
\end{tabular}

The intervals between the quoted wavelength regions, such as between 12 to 14 microns and 16 to 21 microns, are characterized by overlapping bands and semitransparent gaps. The radiance of these intervals is somewhere between that of the strong absorption regions of the gases discussed and that of the window chosen for this investigation. The ranges less than 6 microns and greater than 125 microns are of minor interest, since the fraction of thermal energy available in these spectral ranges is diminishingly small.

The fraction of the radiance emitted by the earth and the atmosphere, which can be detected by a horizon sensor with a spectral response $\phi_{\lambda}$, is given by

$$
N_{\phi}=-\frac{1}{\pi} \int_{\lambda=0}^{\infty} \int_{u=0}^{\infty} \phi_{\lambda} B_{\lambda}(T) \frac{\partial \tau\left(u^{*}\right)}{\partial u^{*}} d u^{*} d \lambda .
$$


(All symbols are defined in Appendix A.) For a discussion of radiative transfer equations see, for example, Reference 4. In this calculation, the spectral response $\phi_{\lambda}$ of a possible detection system has been taken as unity within the quoted wavelength ranges and as zero outside. For this specific form of $\phi_{\lambda}$ we redefine $N_{\phi}=N_{\Delta \lambda}$ in Equation 1. The integration of $N_{\triangle \lambda}$ was done graphically, with the aid of radiation charts. The problem can be divided into the following tasks:

1. The formulation of an expression for the reduced optical path $u^{*}$, for a curved atmosphere as a function of height, and for various gas pressures, temperatures, and concentrations;

2. The selection of atmospheres of extreme but realistic properties to show the limits that can reasonably be expected in the apparent horizon;

3. Numerical computation of $u^{*}$ for each gas and atmosphere selected;

4. Construction of a radiation chart for each spectral range under consideration; and

5. The plotting and graphical evaluation of the radiation charts for all spectral ranges and atmospheres.

The results of the integrations are summarized in diagrams, and the problem is discussed in the sequence previously listed.

\section{THE REDUCED OPTICAL PATH}

The reduced optical path du* of an absorber has been taken from Elsasser (Reference 5), and its relation to the true optical path du is expressed by

$$
\text { du* }-\frac{P}{P_{0}}\left(\frac{T_{0}}{T}\right)^{1 / 2} d u
$$

The factors $\mathrm{P} / \mathrm{P}_{0}$ and $\left(\mathrm{T}_{0} / \mathrm{T}\right)^{1 / 2}$ take into account the pressure and temperature dependence of line width. In these computations the above expression for the reduced optical path $\mathrm{u}^{*}$ was used for all gases except for ozone when the pressure exceeded $10 \mathrm{~cm} \mathrm{Hg}$, after which a constant factor $\mathrm{P}_{1} / \mathrm{P}_{0}$ replaced $\mathrm{P} / \mathrm{P}_{0}$. As pointed out by Elsasser, the results obtained by his replacement are in better agreement with the experimental results on ozone absorption given by Walshaw (Reference 6 ) than are those retaining the $\mathrm{P} / \mathrm{P}_{0}$ factor.

For all gases at high altitudes, where the absorber concentration is low, most of the lines that form an absorption band have not yet reached total absorption in the center of the lines and absorption is linearly proportional to the amount of gas and independent of pressure. Therefore, the pressure and temperature correction applied at these heights introduces a small error. Also, the effect of Doppler broadening on lines was neglected but should be considered for heights greater than about $50 \mathrm{~km}$ (Reference 7; see also Reference 8). It is believed, however, that these effects are relatively unimportant compared to the uncertainties in the temperature profiles and distributions of water vapor and ozone in the higher atmosphere. 


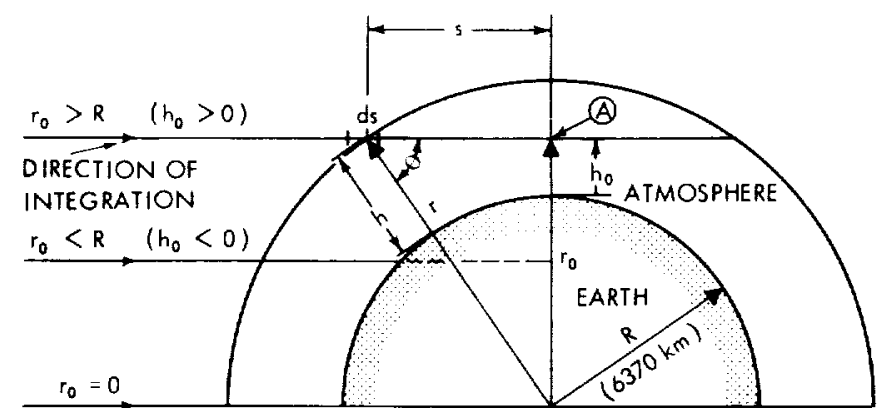

Figure 1-Geometry for the calculations.
The computations were performed for a concentrically stratified atmosphere (see Figure 1)-the distributions of absorbing gases, clouds, temperatures, and pressures then being functions only of height.

Since $d u=q d s$, the reduced optical path $u^{*}$, corrected for pressure and temperature, is given by

$$
u^{*}=+\int_{s=-\infty}^{s} \frac{P(s)}{P_{0}}\left(\frac{T_{0}}{T(s)}\right)^{1 / 2} q(s) d s=-\int_{r=+\infty}^{r} \frac{P(r)}{P_{0}}\left(\frac{T(T)}{T(r)}\right)^{1 / 2} q(r) \frac{r}{\left(r^{2}-r_{0}^{2}\right)^{1 / 2}} d r
$$

The integration along the path $\mathrm{s}$ has to be performed from the top of the atmosphere to a level $\mathrm{r}$ but not farther than to the point where the particular ray comes closest to the surface (e.g., for $r_{0}<R$, to the surface and, for $r_{0}>R$, to point $A$ in Figure 1).

The refraction of rays in the density gradient has been neglected. Although the refraction of individual rays in the density gradient may not be entirely negligible, in the problem of horizon sensing this effect would to the first approximation cancel because of symmetry about the local vertical. For this reason, refraction has been neglected in this investigation. For $r_{0}=0$ we obtain the value of $u^{*}$ required for the calculation of the radiance leaving the atmosphere in the direction of the radius vector. Equation 3 can be used also to investigate the limb-darkening effect as a function of the zenith angle $\theta$, since $r_{0}=r \sin \theta$. The radiation chart used easily permits the second symmetrical half of the atmosphere (to the right of point $A$ in Figure 1) to be taken into account. The radiation chart also deals in a simple manner with clouds and the surface of the earth, and therefore these parameters do not have to be considered here in the computation of $u^{*}$.

The pressure $P(h)$ chosen for a particular model atmosphere was computed separately by numerically integrating the hydrostatic equation

$$
P(h)=P_{0} \exp -\int_{0}^{h} \frac{g(h)}{R_{d} T(h)} d h .
$$

The gas constant for dry air $R_{d}$ has been taken as $2.8704 \times 10^{6} \mathrm{~cm}^{2} / \mathrm{sec}^{2}-{ }^{\circ} \mathrm{K}$. (The effect of atmospheric water vapor on the mean molecular weight of air has been neglected; altitude corrections for $g(h)$, although small, have been made.) The function $q(r)$ in Equation 3 gives the distribution of the absorbing gas. For $\mathrm{CO}_{2}$ a homogeneous distribution of 0.00031 fractional parts by volume was 
assumed. Consequently, du along the radius vector dr becomes

$$
\mathrm{du}(\mathrm{cm} \mathrm{NTP})=\mathrm{q}_{\mathrm{CO}_{2}}(\mathrm{r}) \mathrm{dr}=31 \frac{\rho_{\mathrm{air}} \mathrm{dr}}{\mathrm{R}_{0}}(\mathrm{~km})
$$

But, since $\rho_{\text {a i r }}=\mathrm{P} / \mathrm{R}_{\mathrm{c} 1} \mathrm{~T}$,

$$
d u(\mathrm{~cm} N T P)=31 \frac{\mathrm{P}}{\mathrm{P}_{0}} \frac{\mathrm{T}_{0}}{\mathrm{~T}} \mathrm{dr} \quad(\mathrm{km})
$$

and

$$
\mathrm{u}^{*} \mathrm{Co}_{2}(\mathrm{~cm} \mathrm{NTP})=-31 \int_{m}^{\mathrm{r}}\left(\frac{\mathrm{P}(\mathrm{r})}{\mathrm{P}_{0}}\right)^{2}\left(\frac{\mathrm{T}_{0}}{\mathrm{~T}(\mathrm{r})}\right)^{3 / 2} \frac{\mathrm{r}}{\left(\mathrm{r}^{2}-\mathrm{r}_{0}^{2}\right)^{1 / 2}} \mathrm{dr}(\mathrm{km}) .
$$

Similar considerations for water vapor and ozone yield

$$
\begin{aligned}
\mathrm{u}_{\mathrm{H}_{2} \mathrm{O}}^{*}\left(\mathrm{~cm} \text { precip. } \mathrm{H}_{2} \mathrm{O}\right) & =-0.1292 \int_{\infty}^{\mathrm{r}}\left(\frac{\mathrm{P}(\mathrm{r})}{\mathrm{P}_{0}}\right)^{2}\left(\frac{\mathrm{T} 0}{\mathrm{~T}(\mathrm{r})}\right)^{3 / 2} \mathrm{q}_{\mathrm{H}_{2} \mathrm{O}}(\mathrm{r}) \frac{\mathrm{r}}{\left(\mathrm{r}^{2}-\mathrm{r}_{0}^{2}\right)^{1 / 2}} \mathrm{dr}(\mathrm{km}), \\
\mathrm{U}_{\mathrm{O}_{3}}^{*}(\mathrm{~cm} \mathrm{NTP}) & =-\int_{\infty}^{\mathrm{r}} \frac{\mathrm{P}(\mathrm{r})}{\mathrm{P}_{0}}\left(\frac{\mathrm{T}_{\mathrm{O}}}{\mathrm{T}(\mathrm{r})}\right)^{1 / 2} \mathrm{q}_{\mathrm{O}_{3}}(\mathrm{r}) \frac{\mathrm{r}}{\left(\mathrm{r}^{2}-\mathrm{r}_{0}^{2}\right)} \frac{1 / 2}{1 / 2}(\mathrm{~km}) .
\end{aligned}
$$

For $\mathrm{O}_{3}$, where $\mathrm{P} / \mathrm{P}_{0} \geq 0.132$, a constant pressure ratio $\mathrm{P}_{1} / \mathrm{P}_{0}=0.132$ was used. The water vapor mixing ratio $\mathrm{q}_{\mathrm{H}_{2} \mathrm{O}}$ is expressed in grams per $\mathrm{kg}$, and $\mathrm{q}_{\mathrm{O}_{3}}$ is given in $\mathrm{cm} \mathrm{NTP}$ per km. (The distinction between specific humidity and mixing ratio of water vapor was neglected in these calculations.) However, before the numerical calculations of w* could be carried out, a number of model atmospheres had to be selected; this is discussed next.

\section{THE SELECTION OF MODEL ATMOSPHERES}

The model atmospheres were designed to illustrate the range of radiation characteristics that might reasonably be expected in the various spectral ranges considered. Accordingly, emphasis has been placed for the most part on the extremes likely to be found in various atmospheric parameters. However, in all cases an effort has been made to keep the models plausible and internally consistent.

Five different temperature profiles were used (Figure 2). These are intended to cover the latitude variations and, in the case of the arctic atmosphere, the seasonal variations. The profiles are:

1. Tropical Atmosphere: The tropical profile given in the Handbook of Geophysics (Reference 9) was used up to approximately $22 \mathrm{~km}$. Above this level the low-latitude standard profile 


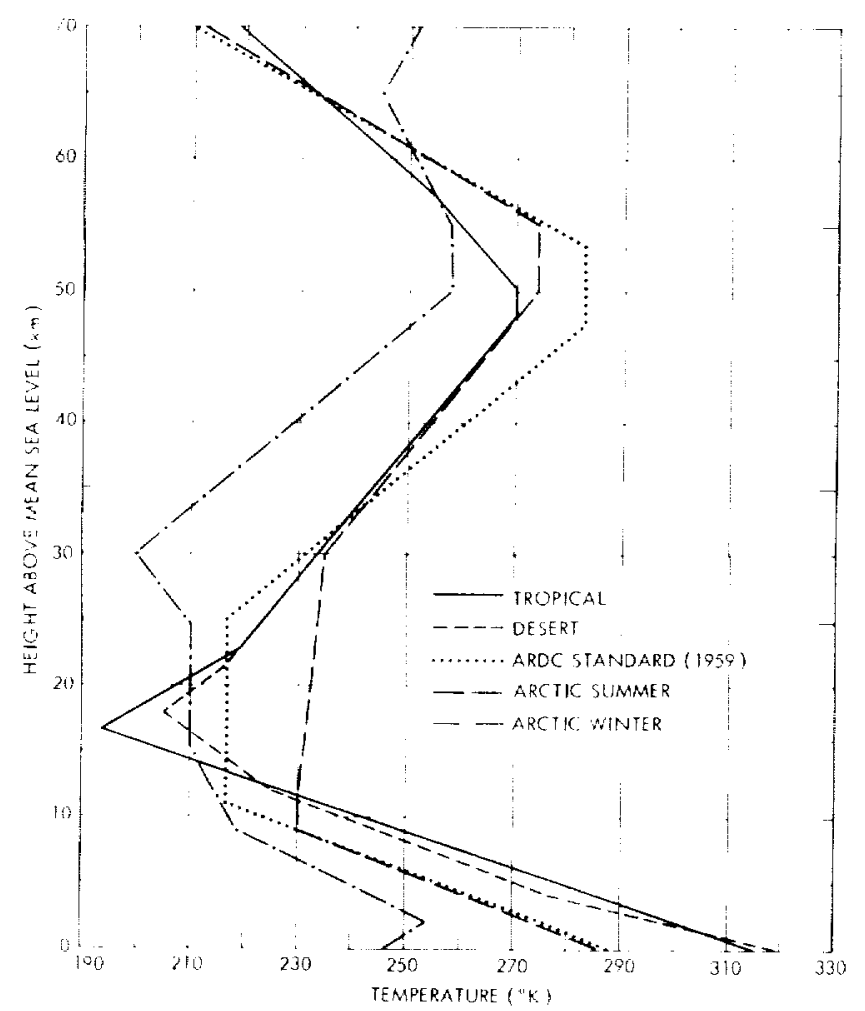

Figure 2-Model atmosphere temperature profiles. proposed by Stroud and Nordberg (Reference $10)$, as determined by sounding rocket measurements on the island of Guam, was used.

2. Desert Atmospher": A linearized average of two desert soundings was used up to $30 \mathrm{~km}$, with the Reference 10 low-latitude standard being incorporated above $30 \mathrm{~km}$. This profile is typical of low-latitude desert regions.

3. ARDC Stamand Atmosphere (1959): This profile (Reference 9 ) is typical of the mid-latitude regions.

4. Arclic Summer Atmsophere: The artic summer profile given in Reference 9 was used up to $30 \mathrm{~km}$. Above $30 \mathrm{~km}$ the high-latitude summer profile given in Reference 10 was adopted. This combination was chosen to give the warmest arctic stratosphere.

5. Arclic Winter Atmosphere: The aretic winter profile as given in Reference 9 was used up to $24 \mathrm{~km}$. Above $24 \mathrm{~km}$, the high-latitude winter profile given in Reference 10 was chosen. This combination was adopted to show the influence of a cold arctic stratosphere.

The distributions of the optically active gases were chosen, as were the temperature profiles, to illustrate the range of conditions that might be expected. The proportion of carbon dioxide in the atmosphere was taken as constant with respect to altitude and latitude, and as equal to 0.031 percent by volume. The water vapor mixing ratios adopted, shown in Figure 3, are described as follows:

1. Tropical Model: Up to $8 \mathrm{~km}$, mixing ratios based on a linearization of a Trinidad, West Indies, sounding (1200 UT, 20 July 1961) were used. This sounding was chosen as representative of a very moist tropical troposphere. From 8 to $20 \mathrm{~km}$ a constant relative humidity was assumed. From 20 to $31 \mathrm{~km}$ a constant frost point was used, and above $31 \mathrm{~km}$ a constant mixing ratio of $0.11 \mathrm{gm} / \mathrm{kg}$. This combination results in a total of about $5.07 \mathrm{~cm}$ of precipitable water. Temperature profile no. 1 was incorporated in this model.

2. Desert Model: A linearized average of two Aoulef, Algeria, soundings (1200 UT, 16 August 1960; and $1200 \mathrm{UT}, 25$ August 1960) was used up to $17.5 \mathrm{~km}$. From $17.5 \mathrm{~km}$ to $31 \mathrm{~km}$ a constant frost point was assumed, and above $31 \mathrm{~km}$ the mixing ratio was held constant at 0.06 $\mathrm{gm} / \mathrm{kg}$. This results in a total of $0.9 \mathrm{~cm}$ precipitable water.

3. Arctic Summer Model; The water vapor mixing ratios were taken from the altitude and latitude distributions of water vapor given by Manabe and Möller (Reference 11). 
4. Arctic Winter Model: The mixing ratios for this atmosphere were taken from Reference 11 .

5. ARDC Standard Atmosphere (1959): A representative mixing ratio profile was adopted, resulting in a total of $1.16 \mathrm{~cm}$ precipitable water.

The four Ozone Models chosen, shown in Figure 4, are described below:

1. Tropic Model: Temperature profile no. 1 was employed along with the ozone distribution for 5 N latitude used in Reference 11.

2. Mid-Latitude Model (Arosa normal): An ozone distribution based on a 3-year mean (19561958) of measurements made at Arosa, Switzerland, $47^{\circ} \mathrm{N}$ (Reference 12) was chosen along with temperature profile no. 3 .

3. Disturbed Mid-Latitude Model (Arosa high): This model was constructed as an illustration of the rapid changes that might be encountered at any given point as the result of the passage of frontal systems. The ozone distribution used is that given in Reference 12 based on measurements taken after the

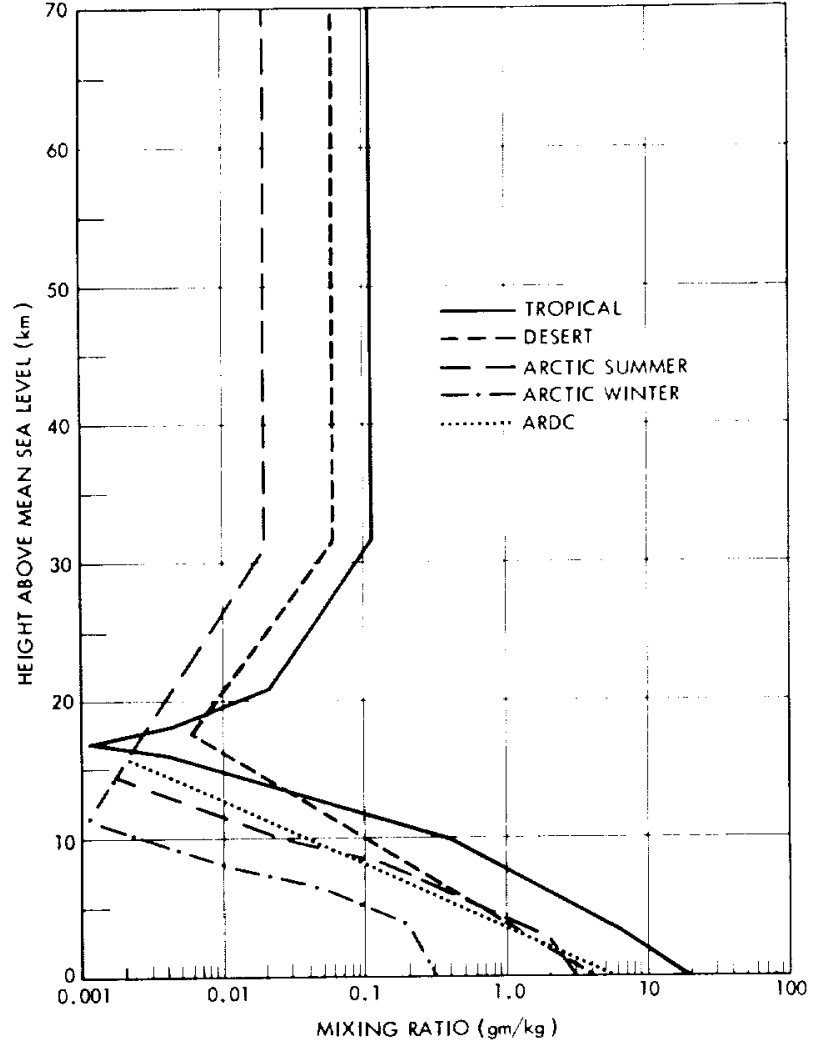

Figure 3-Model atmosphere water vapor mixing ratios. Above about $15 \mathrm{~km}$, the ARDC and arctic winter mixing ratios are coincident with those of the arctic summer.

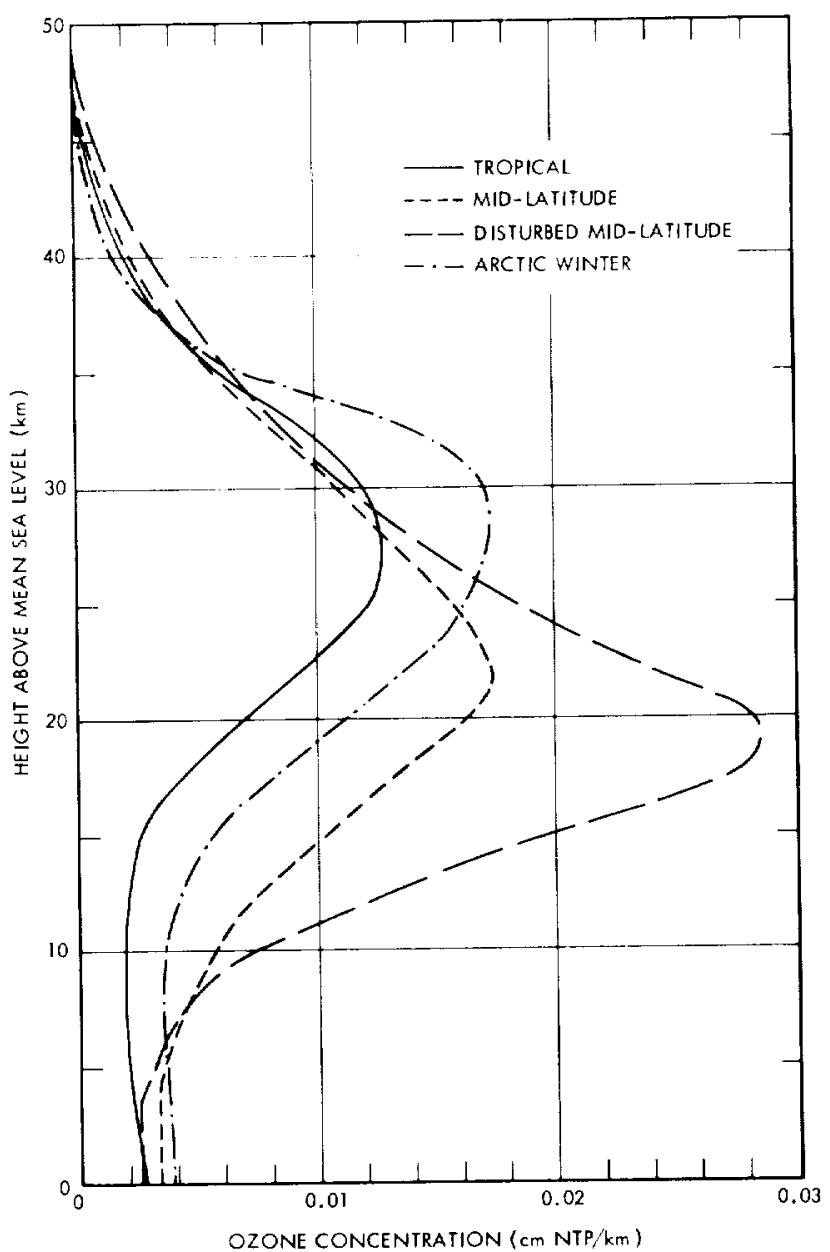

Figure 4-Model atmosphere ozone distribution. 
passage of a pronounced cold front. As in the Arosa normal case, temperature profile no. 3 was used.

4. Arctic Winter Model: Temperature profile no. 5 was used in this model along with the Manabe and Möller (Reference 11) distribution of ozone for January at $85^{\circ} \mathrm{N}$.

\section{NUMERICAL COMPUTATION OF $\mathbf{u}^{*}$}

A large number of values of $u^{*}$ had to be calculated for each case to allow curves of $u^{*}$ versus , to be plotted on the radiation diagrams. For these calculations Equations 6, 7, and 8 were solved for carbon dioxide, water vapor, and ozone, respectively, on an IBM 7090 Computer. The integration over $\mathrm{r}$ was carried out by a straight summation using intervals of $0.05 \mathrm{~km}$, initiated at $\mathrm{h}_{\max }=70 \mathrm{~km}$.

\section{CONSTRUCTION OF RADIATION CHARTS}

A radiation diagram was constructed for each of the five spectral regions chosen. The various types (Möller, Elsasser, Yamamoto, etc.) are similar in their basic concept and can be transformed into each other by conformal mapping. Möller's (Reference 4) version of the diagram and Elasser's (Reference 5) generalized absorption coefficients were adopted. For the computations, each region was divided into a number of spectral intervals for which a constant absorption coefficient was assumed. The values adopted are summarized in Table 2.

Table 2

Absorption Coefficients Adopted for the Calculations.

\begin{tabular}{|c|c|c|c|}
\hline Major Absorber & $\begin{array}{c}\text { Wavelength } \\
\text { (microns) }\end{array}$ & $\begin{array}{l}\text { Band Absorption, } \\
\tau=\tau\left(\mathrm{Lu}^{*}\right) \\
(\log \mathrm{L})\end{array}$ & $\begin{array}{l}\text { Absorption by Continuum, } \\
\begin{array}{c}\tau=\exp \left(-k u^{*}\right) \\
(\log k)\end{array}\end{array}$ \\
\hline $\mathrm{H}_{2} \mathrm{O}$ & $\begin{array}{l}6.33=6.5 \\
6.5=6.67 \\
6.67=6.85\end{array}$ & $\begin{array}{r}+2 \\
0.4+2 \\
+2 \\
\end{array}$ & $\begin{array}{l}\overline{-} \\
-\end{array}$ \\
\hline $\mathrm{O}_{3}$ & $\begin{array}{l}8.9-9.35 \\
9.35-9.9 \\
9.9-10.1\end{array}$ & $\begin{array}{l}0.8-2 \\
0.2-1 \\
0.6-1\end{array}$ & $\begin{array}{l}- \\
-\end{array}$ \\
\hline $\begin{array}{l}\text { Window } \\
\left(\mathrm{H}_{2} \mathrm{O} \text { continuum }\right)\end{array}$ & $10.75-11.75$ & $0.7-5$ & $0.85-2$ \\
\hline $\mathrm{CO}_{2}$ & $\begin{array}{ll}14 & -14.5 \\
14.5 & -15.5 \\
15.5 & -16\end{array}$ & $\begin{array}{l}0.6-1 \\
0.3-1 \\
0.6-1\end{array}$ & $\begin{array}{l}- \\
-\end{array}$ \\
\hline $\mathrm{H}_{2} \mathrm{O}$ & $\begin{array}{ll}21 & -25 \\
25 & -30 \\
30 & =40 \\
40 & -125\end{array}$ & $\begin{array}{r}+1 \\
0.6+1 \\
0.2+2 \\
0.6+2\end{array}$ & $\begin{array}{l}- \\
- \\
-\end{array}$ \\
\hline
\end{tabular}


The radiation diagrams for the carbon dioxide band, the window, the ozone band, and the 6.3micron water vapor band are comparatively simple to construct, since the wavelength regions are so small that the distribution of blackbody energy, relative to the spectral intervals into which each region has been divided (Table 2), remains approximately constant over the temperature range of interest. Therefore, lines of constant temperature are horizontal.

The above simplification, however, does not hold for the broad wavelength region being considered within the rotational band of water vapor. For the computation of this radiation diagram, the integral

$$
\int_{\lambda} \mathrm{B}_{\lambda}(\mathrm{T}) \frac{\partial \tau}{\partial \mathrm{u}^{*}} \mathrm{~d} \lambda \approx \sum_{\mathrm{i}} \mathrm{B}_{\Delta \lambda_{\mathrm{i}}}(\mathrm{T}) \frac{\Delta T}{\Delta \mathrm{u}^{*}}
$$

which is necessary in the construction of the ordinate, was approximated by a summation over the same four wavelength intervals shown in Table 2. Here $B_{\triangle \lambda_{i}}$ indicates that the actual fraction of the Planck function bounded by the somewhat broad limits of each of the four wavelength intervals was used, rather than the product of the spectral blackbody radiant emittance at the central wavelength and the wavelength interval, which was used in the numerical calculations for all the other regions.

In the window region, the absorption is mainly determined by the absorption coefficient $k$. The numerical value used in our computation is a factor of 10 higher than the one given by Elsasser (Reference 5), which apparently should be used with $10 u^{*}$. In all computations, the generalized absorption coefficient was considered to be independent of temperature. (The scales in all diagrams were calculated with the aid of the radiation slide rule from the Admiralty Research Laboratory, Teddington, England.)

\section{EVALUATION OF THE RADIATION CHARTS}

The atmospheres discussed previously were plotted on the radiation charts, and the integrations were performed graphically with a planimeter. In the plotting procedure, the part of the atmosphere beyond the closest approach to the earth (to the right of point $A$ in Figure 1) was taken into account by imaging the temperature profile in the radiation diagram at the $u^{*}$ value corresponding to $r=r_{0}$ (Figure 5). In cases where the atmosphere was transparent enough to make the surfaces contribute to the outgoing radiation, the surface was assumed to radiate as a blackbody at the temperature indicated by the lowest point of the particular temperature profile. This effect occurs, for example, in the window case for the arctic winter atmosphere (Figure 6).

In addition to the clear-sky states of the model atmospheres, high cloud overcasts were introduced into all except the desert atmosphere. The clouds, too, were assumed to radiate as blackbodies at the ambient temperatures associated with the heights of cloud tops. To illustrate extreme cases, the cloud-top heights have been considered to be at the tropopause-and therefore at the lowest temperature-for the tropical atmosphere $(16.8 \mathrm{~km})$, as shown in Figure 7, and for the arctic summer atmosphere $(9.0 \mathrm{~km})$. For the standard atmosphere, the cloud-top height has been placed in the minimum temperature isothermal region at $12.0 \mathrm{~km}$, a representative level considering the variation in the 


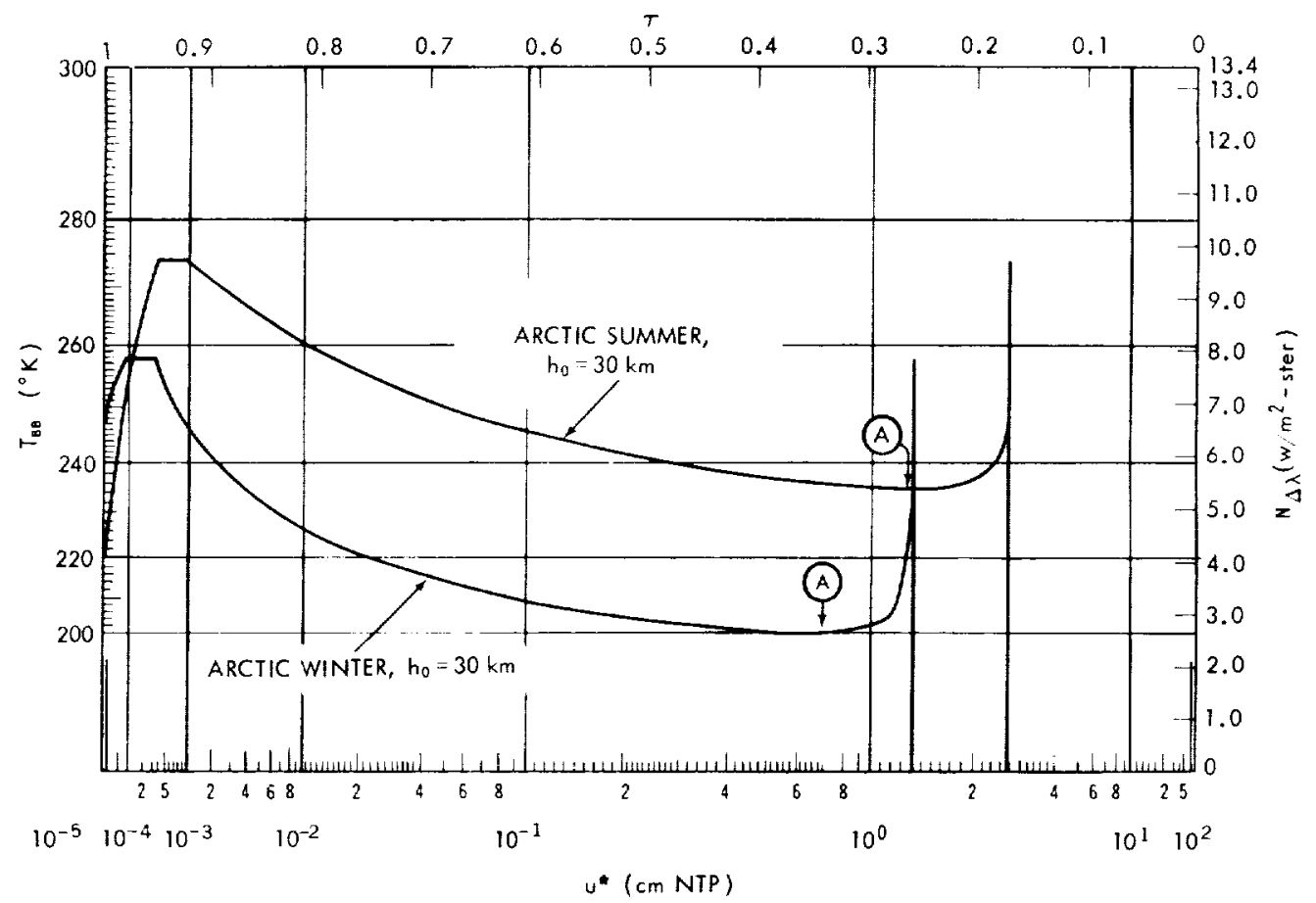

Figure 5-Radiation chart for the 15 micron $\mathrm{CO}_{2}$ band. Radiance values correspond to the area under each curve. The right-hand portion of each curve is an image of the plot to the left of point $A$. The lower arctic winter radiance is caused by lower temperatures and lower air densities in the upper atmosphere.

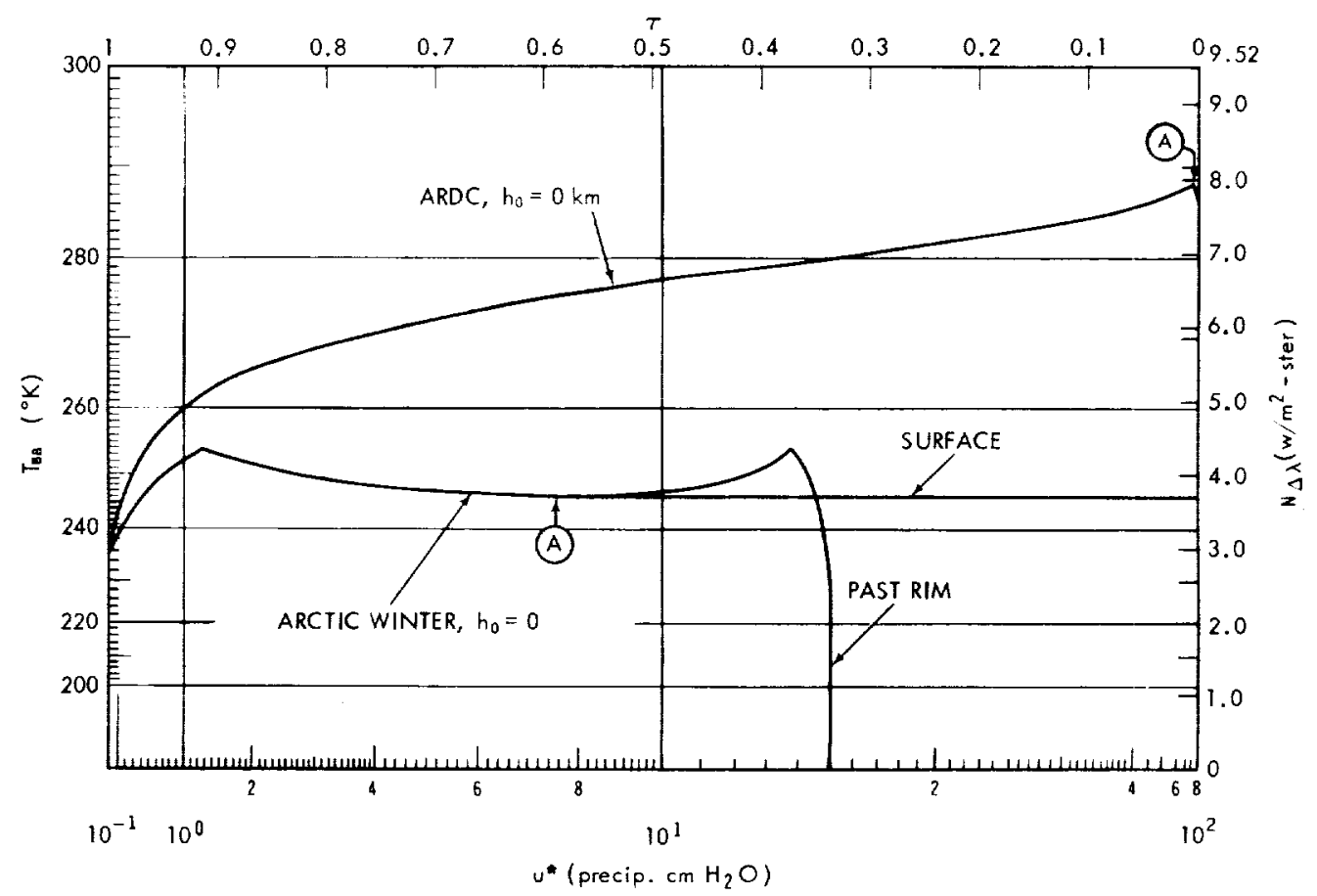

Figure 6-Radiation chart for the atmospheric window. When the atmosphere is not opaque, two solutions exist for $h_{0}=0$, viz., when the ray is terminated at the surface and when the ray extends past the rim of the earth. 


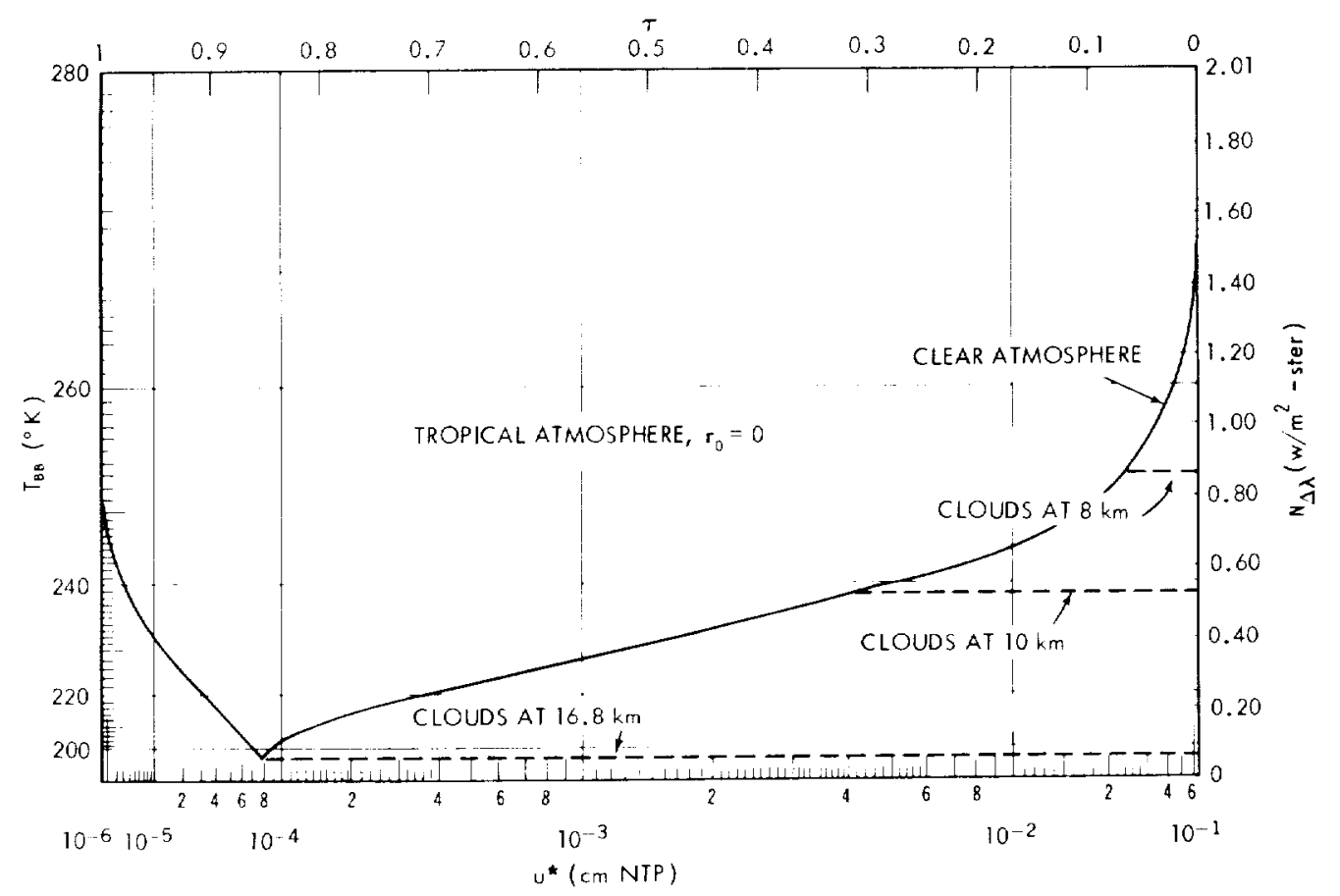

Figure 7-Radiation chart for the 6.3 micron $\mathrm{H}_{2} \mathrm{O}$ band. The effect of clouds acting as blackbody radiators at various heights in the tropical atmosphere is illustrated.

height of the tropopause over middle latitudes. Considering the often ill-defined tropopause at high latitudes in the winter, the cloud-top height has been placedat $8.5 \mathrm{~km}$ for the arctic winter atmosphere. This level is near the mean winter tropopause height at high latitudes according to Kochanski (Reference 13 ).

The radiation chart of the rotational water vapor band (Figure 8) shows samples of the desert atmosphere. The decrease of $N$ (area under each curve) with rising values of $h_{0}$ is caused by a rapid reduction in the absorbing gas. This rapid decrease is partially compensated by a simultaneous increase in radiance per unit $\lambda_{7}$ as a result of the positive, vertical temperature gradient in the stratosphere and the shape of the isothermal lines in the radiation chart. The point $A$, for example, rises $20^{\circ}$ from the curve corresponding to $h_{0}=25$ to the one corresponding to $35 \mathrm{~km}$. The high transparency of the zone above $25 \mathrm{~km}$ shifts the weight of the emitted radiation towards the range that possesses the highest absorption coefficient, that is, towards the long wavelength end of the 21 to 125 micron interval (see Table 2). There the Planck function is less sensitive to small temperature changes, which is the physical reason for the rise of the isothermal lines at the left side of the radiation chart.

Special attention must be given to the second important absorber within each wavelength region. Only in the range between 8.9 and 10.1 microns was it necessary to consider two gaseous absorbers quantitatively, namely, ozone and the water vapor continuum. This was done, as shown in Figure 9, by plotting the calculated transmissivity curve $\tau-\tau_{\mathrm{O}_{3}} \cdot \gamma_{\mathrm{H}_{2} \mathrm{O}}$ and integrating over it. The absorption coefficients for the window (10.75 to 11.75 microns) were used to compute ${ }^{\tau_{\mathrm{H}} \mathrm{O}}$. 


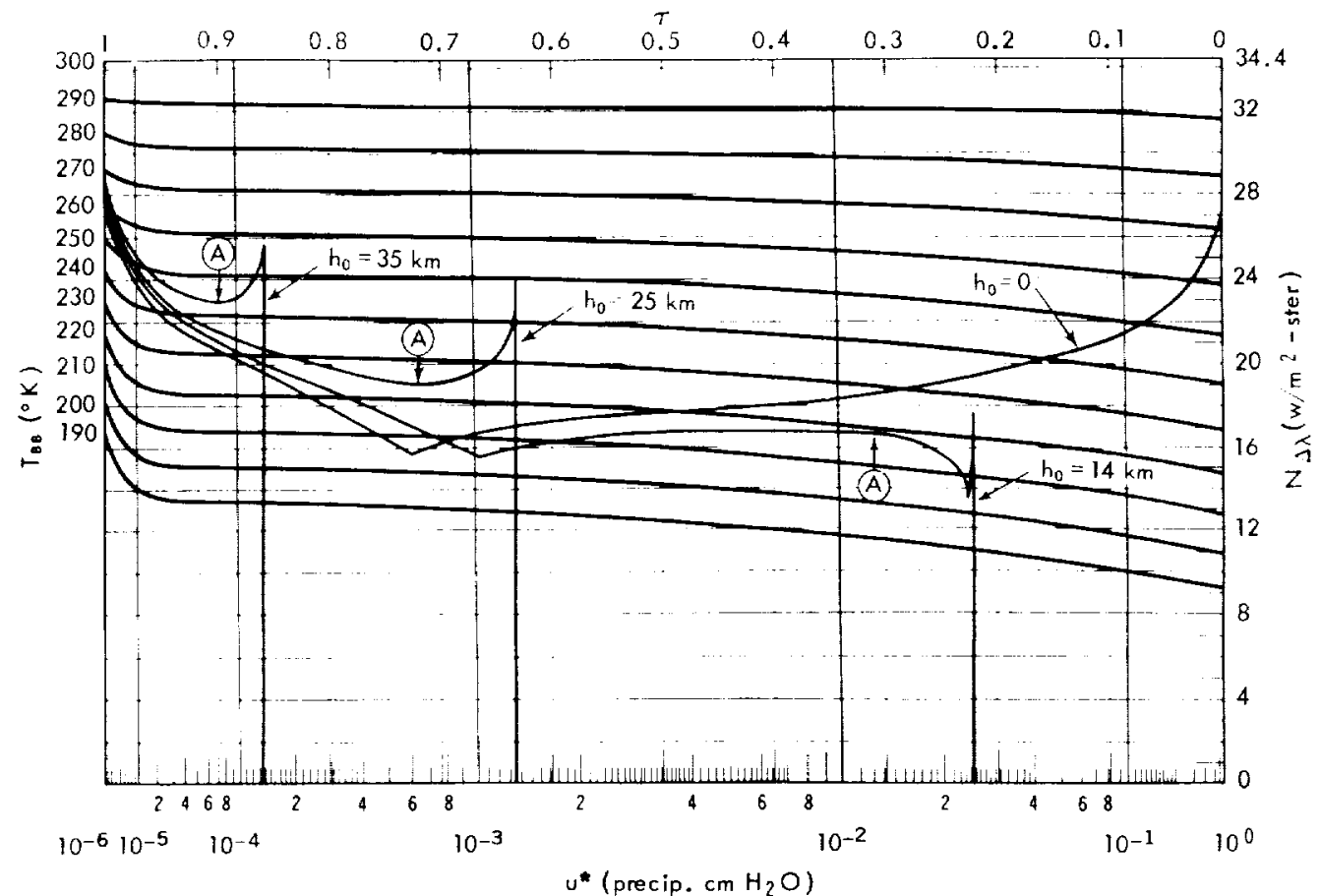

Figure 8-Radiation chart for the rotational $\mathrm{H}_{2} \mathrm{O}$ band. Curves are plotted on the desert atmosphere for various values of $h_{0}$.

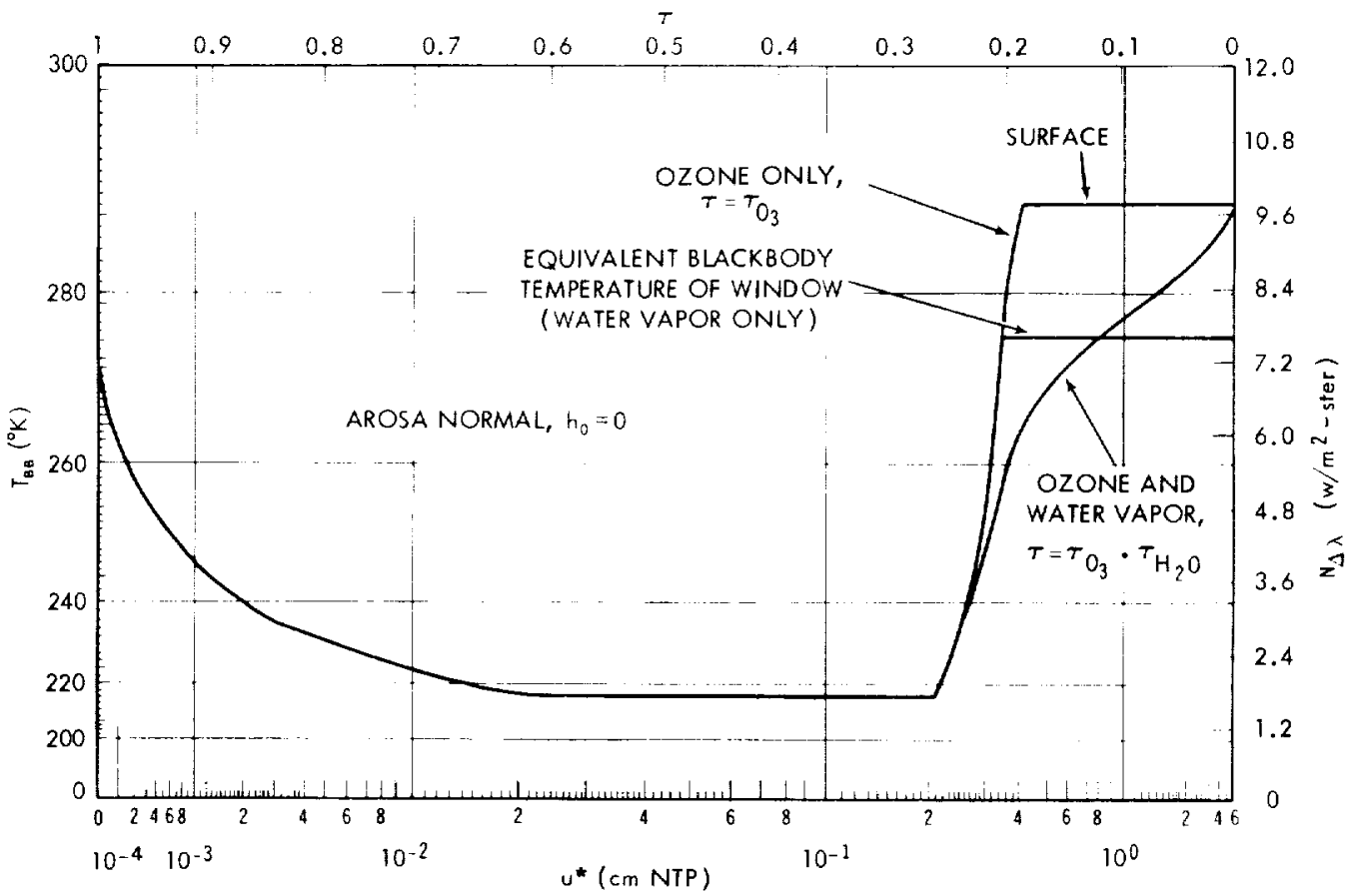

Figure 9-Radiation chart for the 9.6 micron $\mathrm{O}_{3}$ band. Three curves are illustrated: (1) where the transmission is due to $\mathrm{O}_{3}$ only; (2) where the first curve is terminated at the equivalent blackbody temperature of the window (considering the entire atmosphere); and (3) where the transmission is taken as the product of the transmissions due to both $\mathrm{O}_{3}$ and $\mathrm{H}_{2} \mathrm{O}$. Note that radiance values calculated from the latter two curves are approximately equal. 
The influence of water vapor on the 14 to 16 micron carbon dioxide emission band can be neglected because of the opaqueness of $\mathrm{CO}_{2}\left(\mathrm{co}_{2}=0.02\right)$ at a level where water vapor is still transparent $\left(\mathrm{H}_{2} \mathrm{O} \geq 0.98\right)$. A similar consideration for the effect of the 14 micron ozone band within the 14 to 16 micron range is not as favorable. In the case of the standard atmosphere, for an $h_{0}$ of zero, the ozone diagram for 14 to 16 microns shows a transmissivity from the surface of only about 0.8 . However, the emission originates mostly from the 10 to $25 \mathrm{~km}$ low temperature range, which also dominates the carbon dioxide diagram. The net effect of the residual $\mathrm{O}_{3}$ emission is then the same as the $\mathrm{CO}_{2}$ emission, and it was therefore neglected.

The window from 10.75 to 11.75 is so transparent that small amounts of solid particles, or droplets, in the air affect transmissivity. For example, cirrus clouds, often invisible from the surface, or dust trapped near the tropopause seem to have more influence on the outgoing radiation in the window than commonly thought (Reference 14). This issue has been neglected, since very little is known about the altitude distribution of aerosols and dust. The effect, if considered, would be a reduction in the radiance emitted from the earth reaching satellite altitudes and a possible increase of radiance in the clear atmosphere for $h_{0}$ values between 5 and $20 \mathrm{~km}$.

\section{RESULTS OF THE INTEGRATION}

The results of the integration are summarized, for each wavelength interval, in Figures 10 through 14. In the diagrams, the radiance $\mathrm{N}\left(\mathrm{w} / \mathrm{m}^{2}-\mathrm{ster}\right)$ within the spectral band and the corresponding blackbody temperature $\left({ }^{\circ} \mathrm{K}\right)$ are plotted versus altitude $h_{0}$ above or below the geometrical horizon $\left(h_{0}=0\right)$. Included at the left side of each figure is the radiance value for $r_{0}=0$, which is the radiance emerging from the earth in the direction of the radius vector.

A comparison of the radiance for $r_{0}=0$ (center of disk) and $h_{0}=0$ (horizon) shows a small but definite limb-brightening effect for all atmospheres in the 14 to 16 micron band (Figure 10). Almost all calculated model atmospheres show a maximum in the vicinity of $+20 \mathrm{~km}$, and an almost identical behavior above $30 \mathrm{~km}$. The arctic winter atmosphere has the same general appearance but deviates somewhat in the absolute levels. The reasons for this are the low temperatures of the upper atmosphere and the associated low densities, which are consistent with the low temperatures in the troposphere. Both effects can be observed in Figure 5 . Clouds have a noticeable influence on the radiance in the tropics only-and there, just near the center of the disk. In the strong carbon dioxide band, the earth appears very uniform with the maximum radiance near the rim and with a generally warmer summer and cooler winter pole.

The appearance of the earth in the atmospheric window (Figure 11) is quite different from that seen in the carbon dioxide region; the slope of the horizon is generally much steeper. Only in the arctic winter case, the geometrical horizon becomes visible. In practice, this will occur rather rarely since, for the most part, clouds will obscure the view, making the disk of the earth appear rather irregular. Enormous changes in the radiance levels from one point of the horizon to an adjacent one must be experted; for example, deserts emitting about $10 \mathrm{w} / \mathrm{m}^{2}-\mathrm{ster}$ may be next to high clouds emitting only $0.9 \mathrm{w} / \mathrm{m}^{2}$-ster. The meteorological situation has a great influence on this 


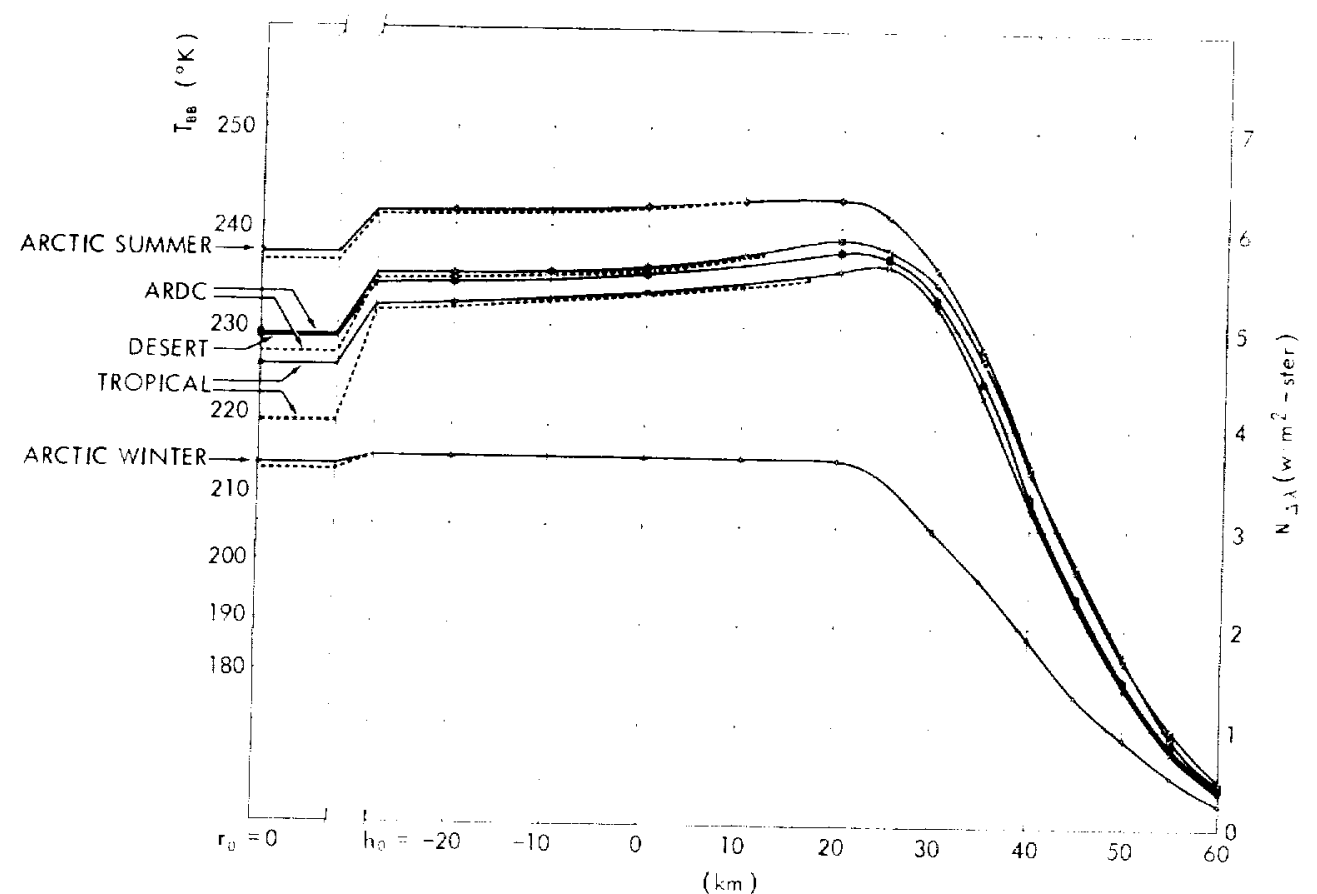

Figure 10-Curves of radiance in the 15 micron $\mathrm{CO}_{2}$ band vs. $h_{0}\left(r_{0}\right)$ for the five model atmospheres. Solid lines represent clear sky, and dashed lines represent high cloudiness conditions.

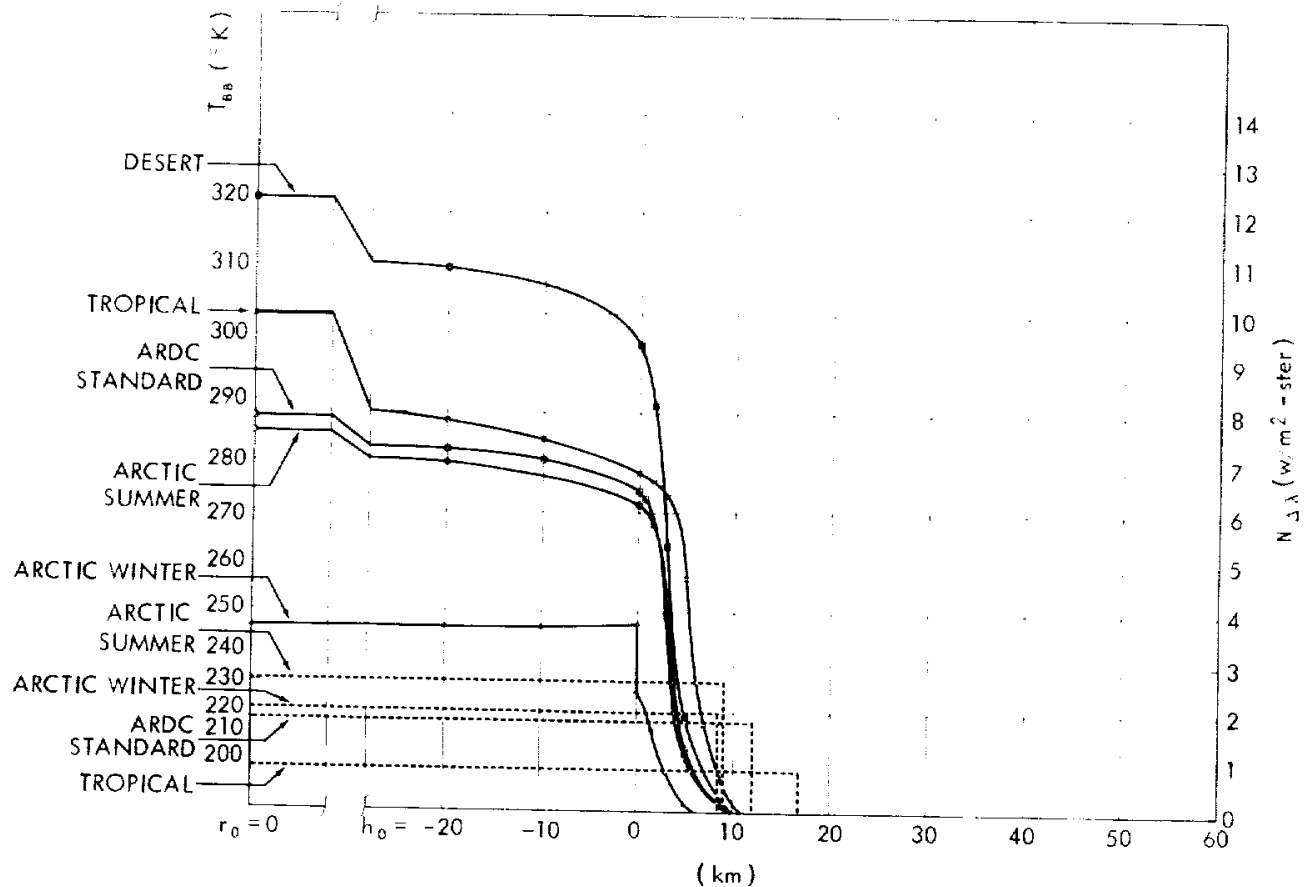

Figure 11-Curves of radiance in the atmospheric window vs, $h_{0}\left(r_{0}\right)$ for the five model atmospheres. Solid lines represent clear sky, and dashed lines represent cloudiness conditions. 


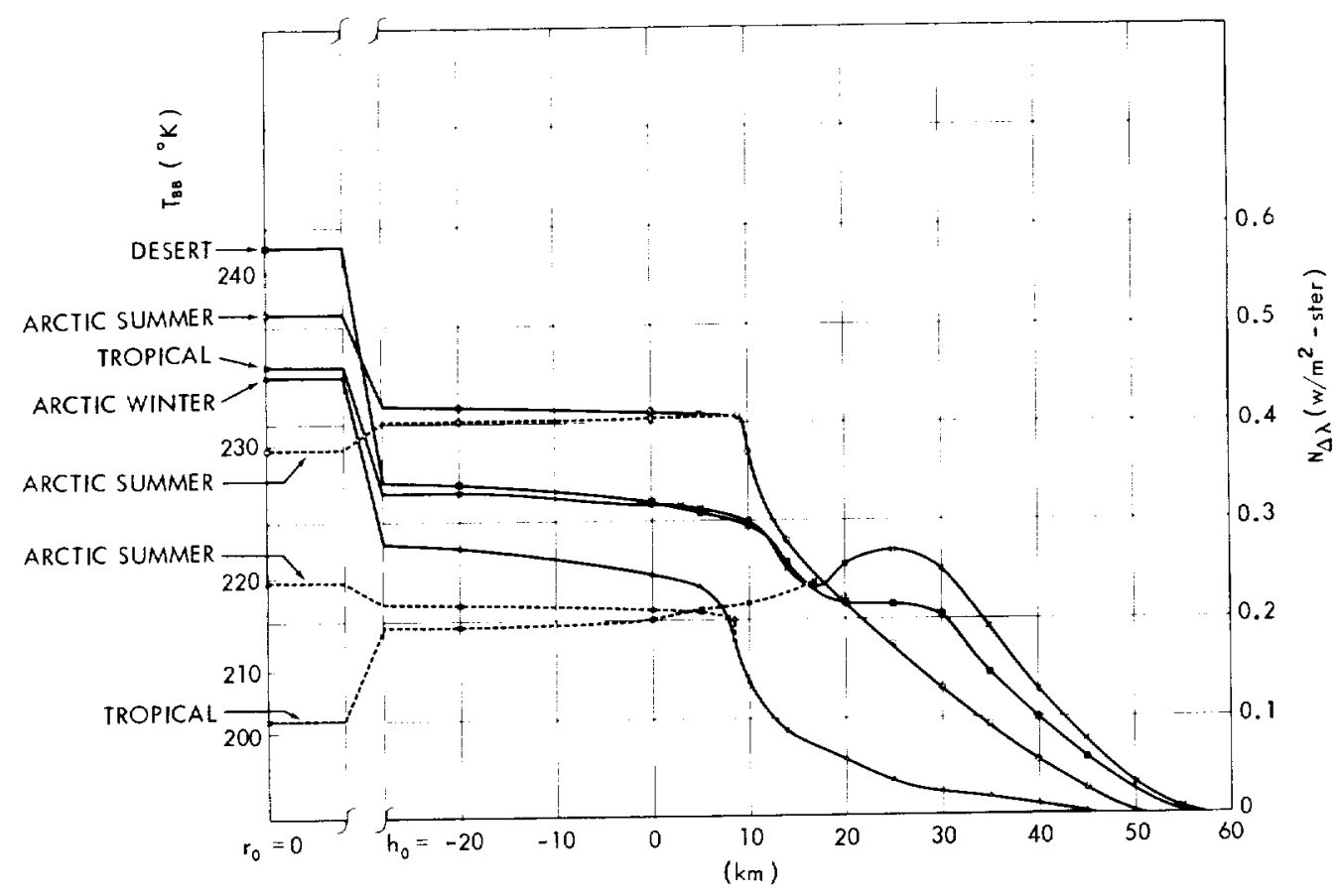

Figure 12-Curves of radiance in the 6.3 micron $\mathrm{H}_{2} \mathrm{O}$ band vs. $h_{0}\left(r_{0}\right)$ for four model atmospheres. Solid lines represent clear sky, and dashed lines represent high cloudiness conditions.

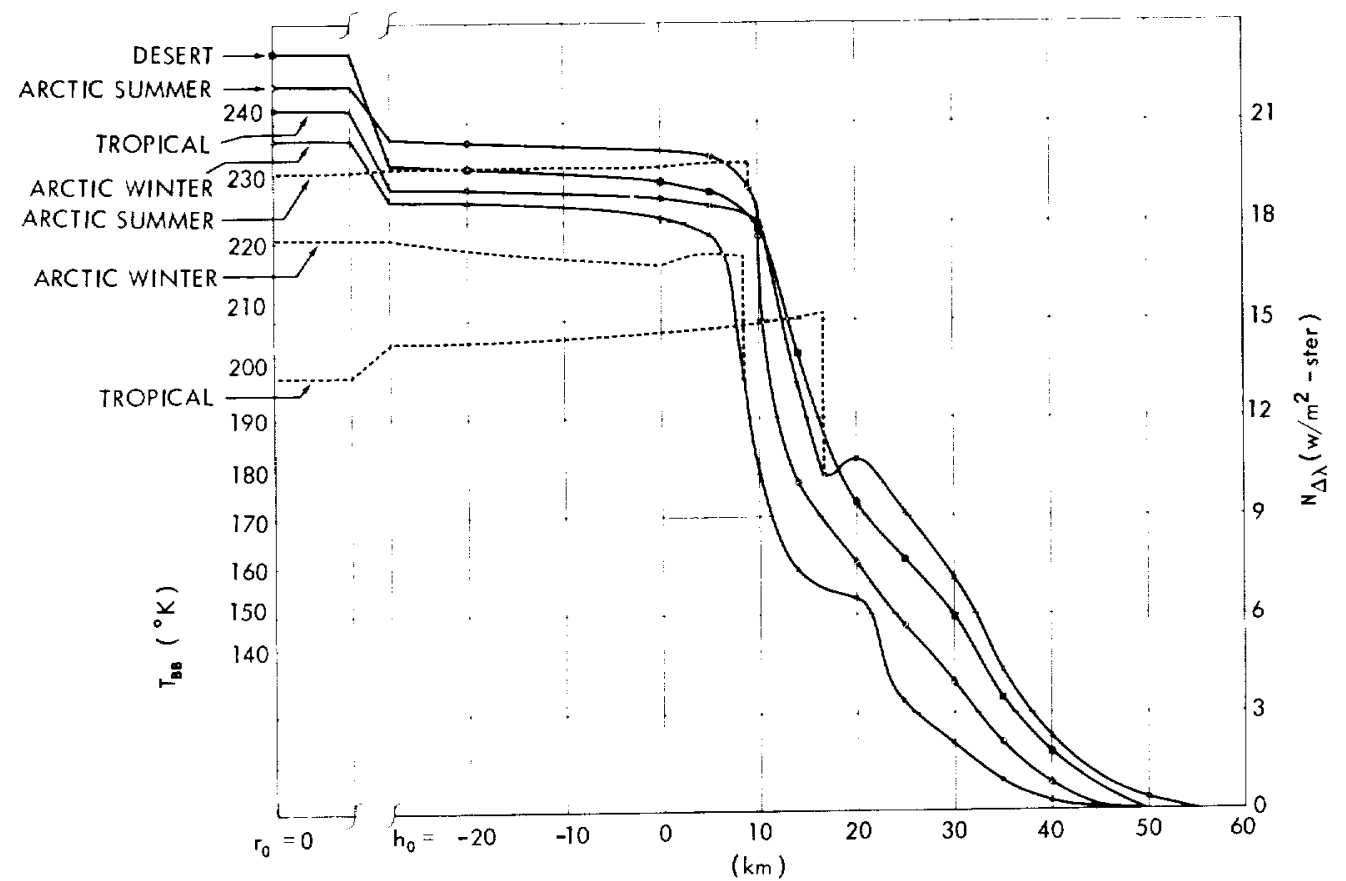

Figure 13-Curves of radiance in the rotational $\mathrm{H}_{2} \mathrm{O}$ band vs. $h_{0}\left(r_{0}\right)$ for four model atmospheres. Solid lines represent clear sky, and dashed lines represent high cloudiness conditions. 


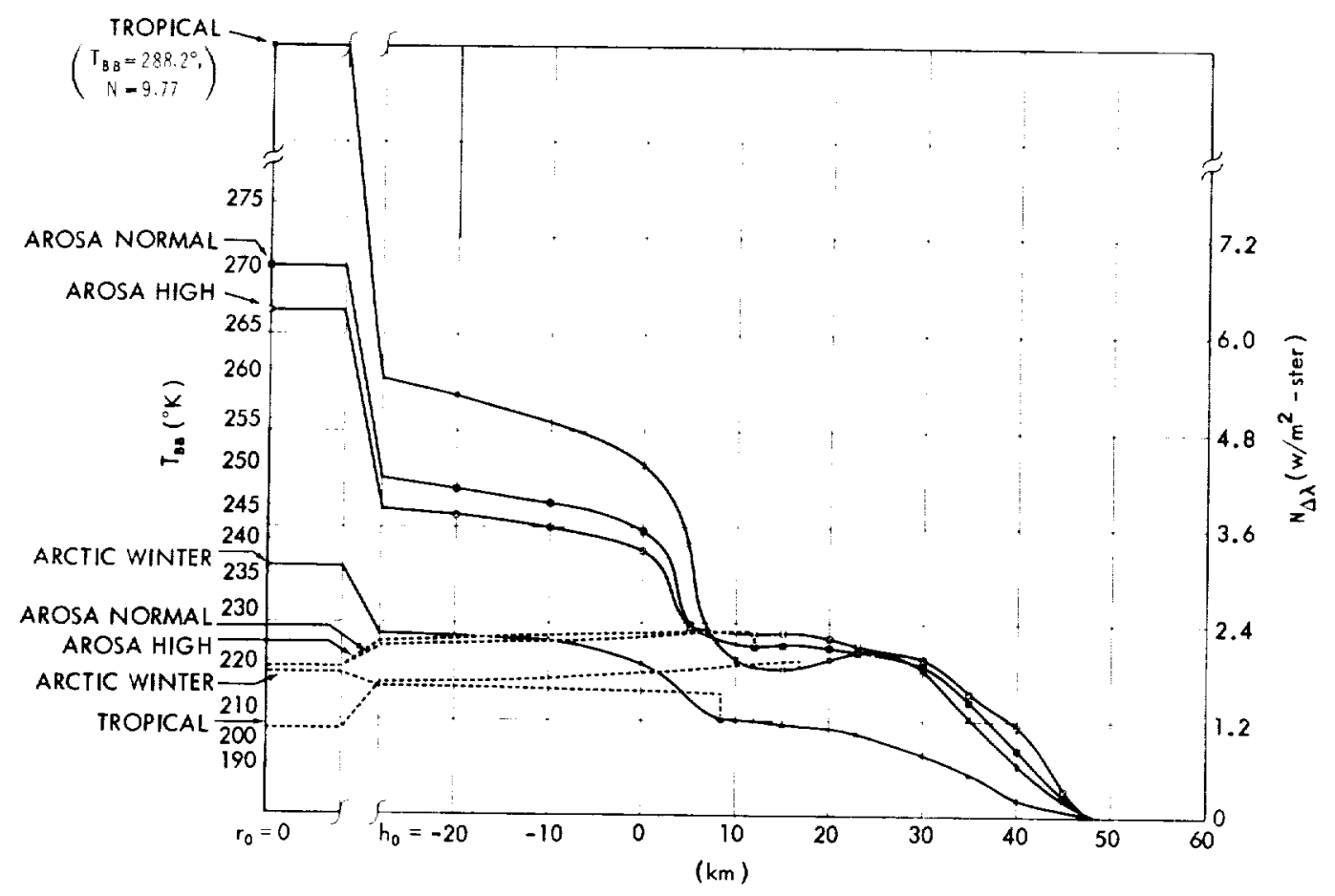

Figure 14-Curves of radiance in the 9.6 micron $\mathrm{O}_{3}$ band vs. $h_{0}\left(r_{0}\right)$ for the tropical Arosa normal, Arosa high, and arctic winter atmospheres. Solid lines represent clear sky, and dashed lines represent high cloudiness conditions.

wavelength region. The threshold of a horizon detector system must be set low enough that high cloudiness will not be mistaken for outer space.

The 6.3 micron water vapor band shows less contrast than the window at the center of the disk, $r_{0}=0$, (Reference 15) and even less near the horizon (Figure 12). The low temperatures at the tropical tropopause and an increase in the water vapor mixing ratio in the stratosphere give rise to a warm zone at $25 \mathrm{~km}$ above a partial minimum near $15 \mathrm{~km}$. The same effect creates a small plateau in the desert atmosphere between 20 and $30 \mathrm{~km}$. Tropical clouds, however, are still visible near the horizon.

The general shape of the horizon in the rotational water vapor band, shown in Figure 13, appears much more favorable, although the absorption coefficients are of the same order of magnitude as in the 6.3 micron band. The reason lies in the energy distribution of the Planck function. The radiance in the 6.3 micron band is proportional almost to the 10 th power of temperature within the temperature limits of $200^{\circ}$ and $250^{\circ} \mathrm{K}$, whereas the rotational water vapor band in this same region is proportional to a power of only 2 or 3 . The contrast between radiance values across the disk of the earth is therefore much less than in the 6.3 micron band. In the water vapor band, all atmospheres show a steep decline at about a $10 \mathrm{~km}$ altitude. Tropical clouds again are visible, and minor humps occur similar to those in the other water vapor band at 6.3 microns.

In the ozone absorption region, shown in Figure 14, the clear atmosphere exhibits a very pronounced limb-darkening effect. Similar to the window region, strong contrasts between clear and 
cloudy areas exist. The stratification of ozone yields a flat minimum or a small plateau between 10 and $30 \mathrm{~km}$, which is analogous to the situation for tropical water vapor. We can even speak of a double horizon, one near $40 \mathrm{~km}$ and the second one near $5 \mathrm{~km}$ - the latter one appearing only under clear sky conditions. A comparison of the Arosa ozone distributions shows a small but interesting phenomenon: An increase of about 50 percent in the ozone content in the upper atmosphere decreases the radiance of the disk (only by a small amount, perhaps 8 percent) but causes a rise in radiance for $h_{0}$ values above $5 \mathrm{~km}$. The arctic winter atmosphere is also exceptionally low in radiance. Again, in the ozone region, clouds contrast strongly augainst clear skies.

\section{COMPARISON OF CALCULATED VALUES TO TIROS RADIATION DATA}

The Tiros meteorological satellite radiation experiment provides observational data for comparison with some of the above calculations. One channel of the radiometer was sensitive to radiation in the 8 to 13 micron region, and it is therefore possible to make a rough comparison with this observed region by combining the calculations for the 10.75 to 11.75 micron and 8.9 to 10.1 micron bands. While the 5 -degree field of view of the Tiros radiometer does not permit sufficiently high resolution of the horizon, it is possible to compare data taken with the sensor axis nadir angle near zero with the calculations made for $r_{0}=0$.

It is assumed that the radiance per wavelength increment seen in the 8 to 13 micron region would be the same as that seen in the 10.75 to 11.75 micron region, with the exception of the 8.9 to 10.1 micron ozone band, where the calculated radiance for that region was used. In this way the total blackbody temperature was derived. The temperature thus calculated for the standard atmosphere and clear skies was $280^{\circ} \mathrm{K}$ compared, for example, with an average of $289^{\circ} \mathrm{K}$ for clear areas over the eastern United States (Reference 16). The calculated temperature for the tropical atmosphere and clouds near the tropopause of $201^{\prime \prime} \mathrm{K}$ compares favorably with the observed temperature over Hurricane Anna of about 204 "K (Reference 17).

The above comparisons show reasonable agreement, considering the strong dependence of the radiance on the temperature profile and gas distributions. A more thorough comparison of observation and theory would necessitate soundings of temperature and gas distributions at the times the satellite data were acquired. Calculations could then be made, using the sounding data, and could be compared with the radiation observations.

\section{CONCLUSIONS}

For the purpose of horizon sensing, the choice of a spectral region is governed by a number of considerations. One important design parameter is the lowest value of radiance $\mathrm{N}_{\min }$ within the disk of the earth. A horizon sensor must identify this level as the earth, in contrast to space. Since in certain design concepts the detector receives radiation only from a small region near the horizon and never from the central part of the disk, the minimum radiance for $h_{0}=0$ is important. Table 3 lists a value $\mathrm{N}_{0}$ slightly below the minimum radiance, which could serve as a conservative estimate of this 
Table 3

Summary of Important Parameters.

\begin{tabular}{|c|c|c|c|c|c|c|c|}
\hline $\begin{array}{l}\text { Wave } \\
\text { (mic }\end{array}$ & $\begin{array}{l}\text { elength } \\
\text { crons) }\end{array}$ & $\begin{array}{c}N_{m 111}\left(r_{0}=0\right) \\
\left(w / m^{2}-s t e r\right)\end{array}$ & $\begin{array}{c}N_{m 1, n}\left(h_{0}=0\right) \\
\left(w / m^{2}-s t e r\right)\end{array}$ & $\begin{array}{c}N_{0} \\
\left(w / m^{2}-s t e r\right)\end{array}$ & $\begin{array}{c}\mathrm{h} \\
(\mathrm{km})\end{array}$ & $\begin{array}{c}\frac{N_{\max }}{N_{\min }} \\
\left(r_{0}=0\right)\end{array}$ & $\begin{array}{c}\frac{N_{\max }}{N_{\min }} \\
\left(h_{0}=0\right)\end{array}$ \\
\hline 6.33 & - 6.85 & 0.102 & 0.201 & 0.08 & 29.2 & 5.69 & 2.05 \\
\hline 8.9 & -10.1 & 1.09 & 1.57 & 0.9 & 14.7 & 8.95 & 2.79 \\
\hline 10.75 & -11.75 & 0.86 & 0.86 & 0.7 & 13.4 & 14.3 & 10.9 \\
\hline 14 & -16 & 3.54 & 3.69 & 3.0 & 13.3 & 1.61 & 1.68 \\
\hline 21 & -125 & 13.3 & 14.7 & 12 & 7.8 & 1.74 & 1.37 \\
\hline
\end{tabular}

threshold value. The difference $\triangle \mathrm{h}$ between the highest and lowest horizon, quoted for the threshold level $\mathrm{N}_{0}$, is important only for sensors capable of resolving the true shape of the horizon.

The curves in Figures 10 through 14 may also be interpreted as time functions obtained from an ideal detector of zero time constant, without noise, and with an infinitely narrow field of view scanning across the horizon. A more realistic time-constant-to-scan speed ratio and a finite field of view can be considered to be bandwidth restrictions (electrical filters) applied to the Fourier spectrum of the horizon functions. The influence of detector noise on horizon determinations was discussed recently by Goetze (Reference 18).

For many instrument designers the ratio between the maximum and the minimum value of $\mathrm{N}$ becomes very significant; these ratios are listed for the center of the disk $\left(r_{0}=0\right)$ and for the horizon $\left(h_{0}=0\right)$.

The great advantages of the long wavelength, high absorption regions between 14 and 16 microns and beyond 21 microns are apparent. The radiance values are higher; uncertainties in the horizon $\Delta \mathrm{h}$ caused by meteorological and seasonal effects are lower; and the contrast across the disk of the earth is low in comparison with the values in the shorter wavelength regions including the window. Unfortunately, instrumental techniques for wavelengths longer than 30 or 40 microns are not as highly developed as those at shorter wavelengths. However, the 15 micron carbon dioxide band is well within the convenient operating range of thermal detectors, and filters are commercially available.

The comparison of spectral regions in Table 3 includes seasonal effects as well as local meteorological phenomena. It can be expected that the two effects enter accuracy considerations in a different manner. For example, the low arctic winter radiance in the 15 micron carbon dioxide band is semi-stationary and could, at least theoretically, be compensated for in the same manner as we could compensate for the equatorial bulge of the earth. Meteorological effects, on the other hand, are more or less random and cannot be compensated for, other than by integration over time and space. From these considerations, the 15 micron band becomes even more attractive. 
Considering both the theoretical and instrumentational aspects of the problem, it is concluded that a scanner sensitive in the interval of approximately 14 to 16 microns is most promising for minimal errors in the determination of the local vertical from a satellite by means of a horizon sensing system.

It is planned to include a 14 to 16 micron scanner on one of the Tiros satellites in the near future in order to compare theoretical with observed results in this spectral interval.

\section{ACKNOWLEDGMENTS}

The authors are grateful to Dr. Fritz Möller of the University of Munich and Dr. D. Q. Wark of the U.S. Weather Bureau for many helpful discussions concerning the contents of this paper.

Also, the authors should like to express their appreciation to Mr. Robert Hite and Mr. Oliver Clark for programming the numerical computations on the computer and to Miss Louise Coury, Mr. William Brastow, Jr., and Mr. Terry Mahuron for their painstaking and careful plotting and graphical evaluation of the radiation charts.

\section{REFERENCES}

1. Wormser, E. M., and Arck, M. H., "Infrared Navigation Sensors for Space Vehicles," in: Guidance' and Control, ed. by R. E. Roberson and J. S. Farrior, New York: Academic Press, 1962, pp. 443-468.

2. Conrath, B. J., "Earth Scan Analog Signal Relationships in the TIROS Radiation Experiment and Their Application to the Problem of Horizon Sensing," NASA Technical Note D-1341, June 1962. (Available from Office of Scientific and Technical Information, Code AFSS-A, NASA Headquarters, Washington 25 , D. C.)

3. Kondratyev, K. Y., and Yakushevskaya, K. E., "The Angular Distribution of the Outgoing Thermal Radiation in the Different Regions of the Spectrum," Proc. 1st Internat. Sympos. on Rockct and Satellite Meteorology, Washington, April 1962, Amsterdam: North-Holland Publ. Co. (In Press.)

4. Möller, F., "Long-Wave Radiation," in: Compendium of Meteorology, ed. by T. F. Malone, Boston: American Meteorological Society, 1951, pp. 34-49.

5. Elsasser, W. M., and Culbertson, M. F., "Atmospheric Radiation Tables," Meteorological Monographs 4(23) August 1960.

6. Walshaw, C. D., "Integrated Absorption by the 9.6 Band of Ozone," Quart. J. Roy. Meteorological Soc. 83(357):315-321, July 1957.

7. Plass, G. N., and Fivel, D. I., "Influence of Doppler Effect and Damping on Line-Absorption Coefficient and Atmospheric Radiation Transfer," Astrophys. J. 117(1):225-233, January 1953. 
8. Goody, R. M., "The Physics of the Stratosphere," Cambridge: University Press, 1954, Chapter 6.

9. U. S. Air Force, Cambridge Research Center, Geophysics Research Directorate, "Handbook of Geophysics," Rev. Ed., New York: Macmillan, 1960.

10. Stroud, W. G., and Nordberg, W., "Seasonal, Latitudinal, and Diurnal Variations in the Upper Atmosphere," NASA Technical Note D-703, April 1961. (Available from Office of Scientific and Technical Information, Code AFSS-A, NASA Headquarters, Washington 25, D.C.)

11. Manabe, S., and Möller, F., "On the Radiative Equilibrium and Heat Balance of the Atmosphere," Monthly Weather Rev. 89(12):503-532, December 1961.

12. Dütsch, H. U., "Vertical Ozone Distribution over Arosa from Three Years' Routine Observation of the Umkehr Effect," Final Rept. on Contract AF 61(514)-905, September 1959. Also: "Vertical Ozone Distribution from Umkehr Observations," Archiv für Meteorologie, Geophysik und Bioklimatologie 11A(2):240-251, 1959.

13. Kochanski, A., "Cross Sections of the Mean Zonal Flow and Temperature Along $80^{\circ} \mathrm{W}, " J$. Meteorology 12(2):95-106, April 1955.

14. Möller, F., and Zdunkowski, W., "Computational Methods of Long Wave Atmospheric Radiation," Universität München, Meteorologisches Institut, Tech. Rept. on Contract AF 61(052)-493, AFCRI, 62-1032, January 1962.

15. Möller, F., "Atmospheric Water Vapor Measurements at 6-7 Microns from a Satellite," Flanet. Space Sci. 5(3):202-206, July 1961.

16. Nordberg, W., Bandeen, W. R., et al., "Preliminary Results of Radiation Measurements from the TIROS III Meteorological Satellite," J. Atmos. Sci. 19(1):20-30, January 1962.

17. Bandeen, W. R., Conrath, B. J., et al., "A Radiation View of Hurricane Anna from the TIROS III Meteorological Satellite," Froc. 1st Internat. Sympos. on Rocket and Satellite Meteorology, Washington, April 1962, Amsterdam: North-Holland Publ. Co. (In Press.)

18. Goetze, D., "Accuracy and Range of Infrared Horizon Sensors as Limited by Detector Noise," ARS J. 32 (7):1039-1044, July 1962. 
Appendix A

\section{List of Symbols}

$B_{\lambda}(T)$ Spectral radiant emittance (Planck function) for a blackbody of temperature $\mathrm{T}$ (watts $/ \mathrm{m}^{2}$ micron) Acceleration due to gravity

h Height above the surface of the earth

$h_{0} \quad$ Height of line s (along radius vector normal to s)

L Generalized absorption coefficient

N Infrared radiance (watts $/ \mathrm{m}^{2}$-ster)

NTP Conditions of normal temperature $T_{0}$ and pressure $P_{0}$

P Atmospheric pressure

$\mathrm{P}_{0} \quad$ Normal pressure $(760 \mathrm{~mm} \mathrm{Hg}, 1013.25 \mathrm{mb})$

$\mathrm{P}_{1} \quad$ Pressure of $10 \mathrm{~mm} \mathrm{Hg}$, above which the pressure correction factor $\mathrm{P} / \mathrm{P}_{0}$ for calculating the $u^{*}$ for ozone remains constant at $\mathrm{P}_{1} / \mathrm{P}_{0}=0.132$

q Distribution function of an optically active gas

$\mathrm{R} \quad$ Radius of assumed spherical earth $(6370 \mathrm{~km})$

$R_{d} \quad$ Gas constant for dry air $\left(2.8704 \times 10^{6} \mathrm{~cm}^{2} / \mathrm{sec}^{2}-{ }^{\circ} \mathrm{K}\right)$

r Geocentric distance

$r_{0} \quad$ Geocentric distance to line $s$ (length of radius vector normal to $s$ )

Straight line path along which the integration of $u^{*}$ is carried out

T Kinetic temperature

$\mathrm{T}_{\mathbf{B} \text { B }}$

Equivalent blackbody temperature corresponding to integrated radiance within a given spectral interval

$\mathrm{T}_{0} \quad$ Normal temperature $\left(0^{\circ} \mathrm{C}, 273.16^{\circ} \mathrm{K}\right)$

u Actual optical thickness of an absorbing (and radiating) gas

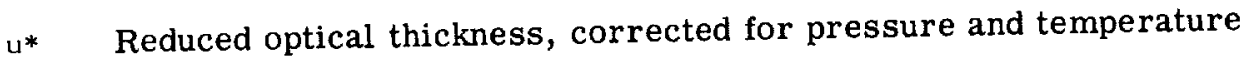

$\theta \quad$ Zenith angle of $s$

$\lambda \quad$ Wavelength (microns)

$\rho_{\text {a i r }}$ Density of air

$\rho_{0} \quad$ Density of air at NTP

$\tau \quad$ Transmissivity for straight line beam radiation

$\phi_{\lambda} \quad$ Spectral response of a sensor

NASA-Langley, $1963 \mathrm{G}-331$ 

